NASA Technical Memorandum 89920

\title{
Detection of Reflector Surface Error From Near-Field Data: Effect of Edge Diffracted Field
}

\author{
Alan R. Cherrette and Shong W. Lee \\ University of Illinois at Urbana-Champaign \\ Urbana, Illinois \\ and \\ Roberto J. Acosta \\ Lewis Research Center \\ Cleveland, Ohio
}

Prepared for the

1987 AP-S International Symposium

sponsored by the Institute of Electrical and Electronics Engineers

Blacksburg, Virginia, June 15-17, 1987

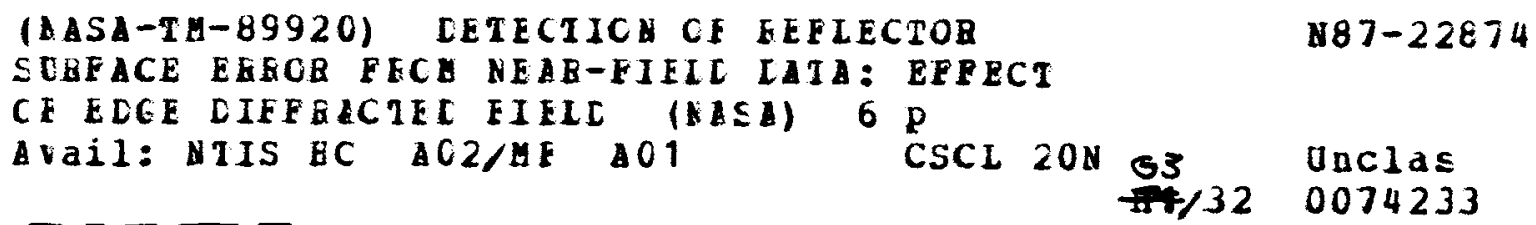


Alan R. Cherrette, Shong W. Lee Electromagnetics Laboratory

Dept. of Elec. and Comp. Engr.

Univ. of Illinois at Urbana-Champaign

Urbana, Illinois 61801
Roberto J. Acosta

National Aeronautics and

Space Administration

Lewis Research Center

Cleveland, Ohio $\mathbf{4 4 1 3 5}$

\section{Int roduction}

The surface accuracy of large reflector antennas must be maintained within certaln tolerances if high galn/low sidelobe performance is to be achleved. Thus, the measurement of the surface profile is an important part of the quality control procedure when constructing antennas of this type. An efficient method for surface profile measurement has been proposed by Parini et al. [1]. In this method, the reflector surface is calculated from the measured near-fleld phase data using the theory of geometric optics.

For a surface profile calculation of this kind, it is necessary to know the margin of error built into the method of calculation. This will enable a specification of the tolerance to which the surface profile can be determined. When calculating the surface profile from near-field phase data, there are two main sources of error. The first source of error $1 \mathrm{~s}$ the measurement error in near-field phase data. The second source of error arises from the edge diffracted fields that are superimposed on the reflected flelds in the measured near-field data. In this paper, we will examine the error in the calculated surface proftle produced by the edge diffracted flelds.

\section{Theory and Calculated Results}

The measured near-field amplitude and phase distribution consists of two parts in the high frequency limit: the reflected fields and the edge diffracted fields. If the edge diffracted fields are neglected, the reflector surface can be determined from the reflected fields in the following manner. Consider the geometry of Figure 1, if one reflection point, $A$, on the reflector surface is assumed to be known, then the length $D$ is known and given by

$$
D=|\vec{F} A|+\left|\overrightarrow{A A}_{\mathbf{a}}\right|
$$

For any other point $P$ on the reflector surface

$D^{\prime}=|\overrightarrow{F P}|+|\overrightarrow{P P}|=\left[x_{a}^{2}+y^{2}+(z-f)^{2}\right]^{1 / 2}+\left[\left(x-x_{a}\right)^{2}+\left(y-y_{a}\right)^{2}+\left(z-z_{a}\right)^{2}\right]^{1 / 2}$

If $\theta\left(P_{a}\right)$ is the phase measured at point $P_{a}$ in the aperture and $\theta\left(A_{a}\right)$ is the phase measured at point $A_{a}$, then the following relation holds

$$
D^{\circ}=\frac{-1}{k}\left[\theta\left(P_{a}\right)-\theta\left(A_{a}\right)\right]+D \text { where } k=\frac{2 \pi}{\lambda}
$$


Note that from the phase data, we also know the equations of the line passing through the points $P$ and $P_{a}$

$$
\begin{aligned}
& \frac{\left(x-x_{a}\right)}{m_{x}}=\frac{\left(z-z_{a}\right)}{m_{z}} \\
& \frac{\left(y-y_{a}\right)}{m_{y}}=\frac{\left(z-z_{a}\right)}{m_{z}}
\end{aligned}
$$

where $\quad m_{x}=\left.\frac{1}{k} \frac{\partial \theta}{\partial x}\right|_{P_{a}}$

$$
\begin{aligned}
& m_{y}=\left.\frac{1}{k} \frac{\partial \theta}{\partial y}\right|_{P_{a}} \\
& m_{z}=\left[1-m_{x}^{2}-m_{y}^{2}\right]^{1 / 2}
\end{aligned}
$$

Equations ( 3 ), (4), and (5) can be solved for the three unknowns $x, y$, and $z$ ylelding a point on the reflector surface.

In any near-fleld measurement, the diffracted flelds are always present and w1ll produce an error in the calculated surface values. To determine this error, the reflected and edge diffracted flelds of a reflector antenna (Figure 2) with known distortion (Figure 3) were calculated at $30 \mathrm{GHz}$. The estlmated reflector surface calculated by the method out lined above was then compared to the exact reflector surface. The difference is plotted in Figure 4. The dot shows the largest value of error in the estimated surface and corresponds to $2.79 \mathrm{mlls}$. The rms error for this case is $0.968 \mathrm{ml}$. This result can be compared to the case where the edge diffracted fields are neglected when calculating the reflector surface (Figure 5). In this case the largest value of error in the estimated surface $1 \mathrm{~s} 0.351 \mathrm{~m} 11$. The rms error is $0.118 \mathrm{mil}$. The error in this case is probably due to the error in parameter $D$ of Equation (1).

\section{Concluston}

The edge diffracted flelds produce an error in the calculated surface profile that gets larger as the edge of the reflector is approached. This is due to the larger relative amplitude of the edge diffracted fields compared with that for the reflected fields near the edge of the near-fleld aperture. For a feed with approximately a $10 \mathrm{~dB}$ edge taper, operating at $30 \mathrm{GHz}$, the error in the surface calculation due to edge diffracted fields is less than $3 \mathrm{mils}$.

\section{$\underline{\text { Reference }}$}

[1] C. G. Parin1, A. K. K. Lau, and P. J. B. Clarricoats, "Reflector Antenna Surface Profile Tolerance Measurement by U1trasound or Microwave Remote-Sensing," 1986 IEEE AP-S Symposium Digest, vol. 1, pp. 119-122. 


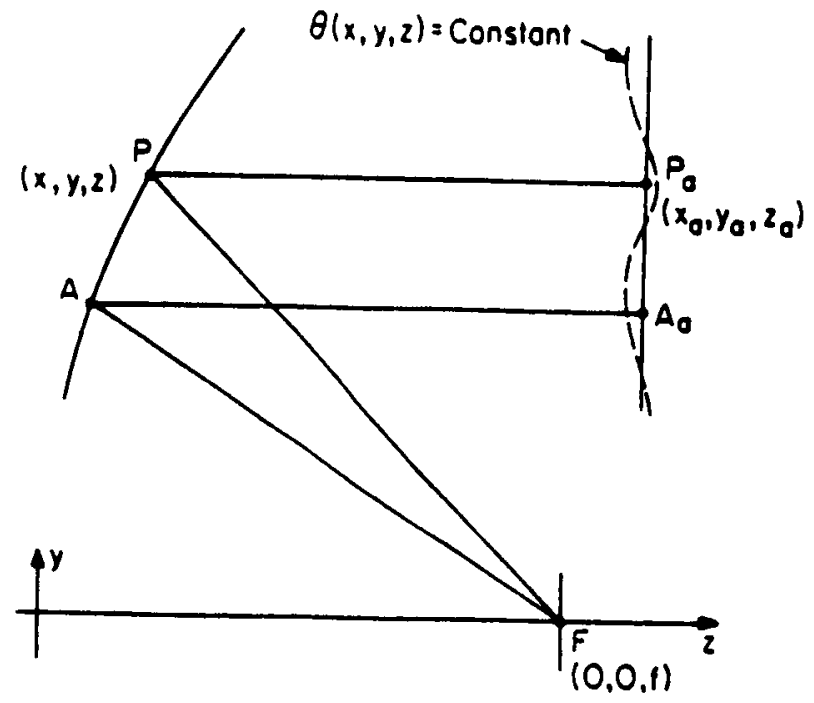

FIGURE 1. Geomrtry for Surface Calculation

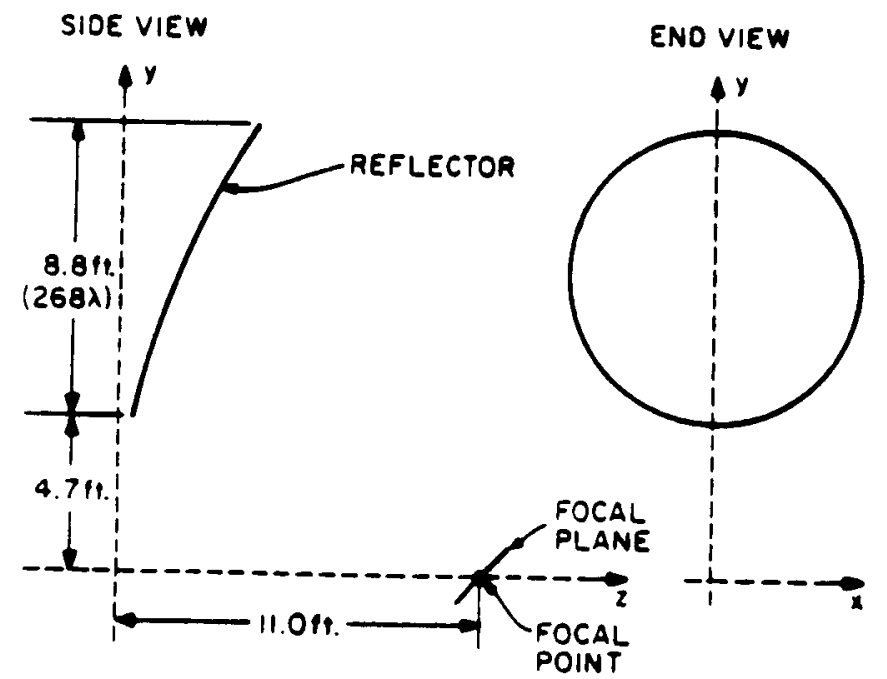

FIGURE 2. Roflector Geometry Used to Obtain the Numerical Results 


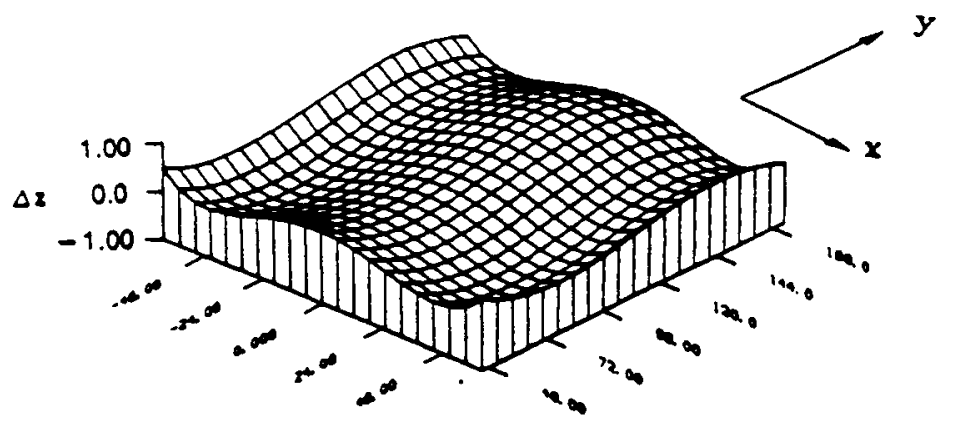

FIGURE 3. Distortion Function Superimposed on the Pertect Parabolk Rofiector

(Height dimension in wavelengths $\odot 30 \mathrm{GHz}$, base dimension in inches)

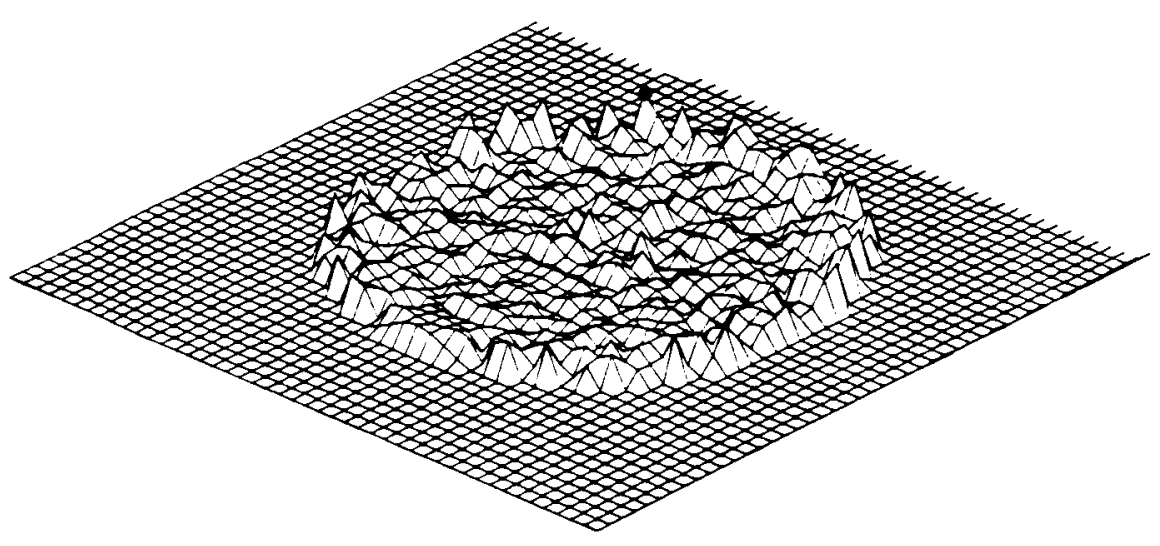

FGURE 4. Error in the z-value of the Calculated Rofiector Surtece when Edge Diffracted Fields are Included

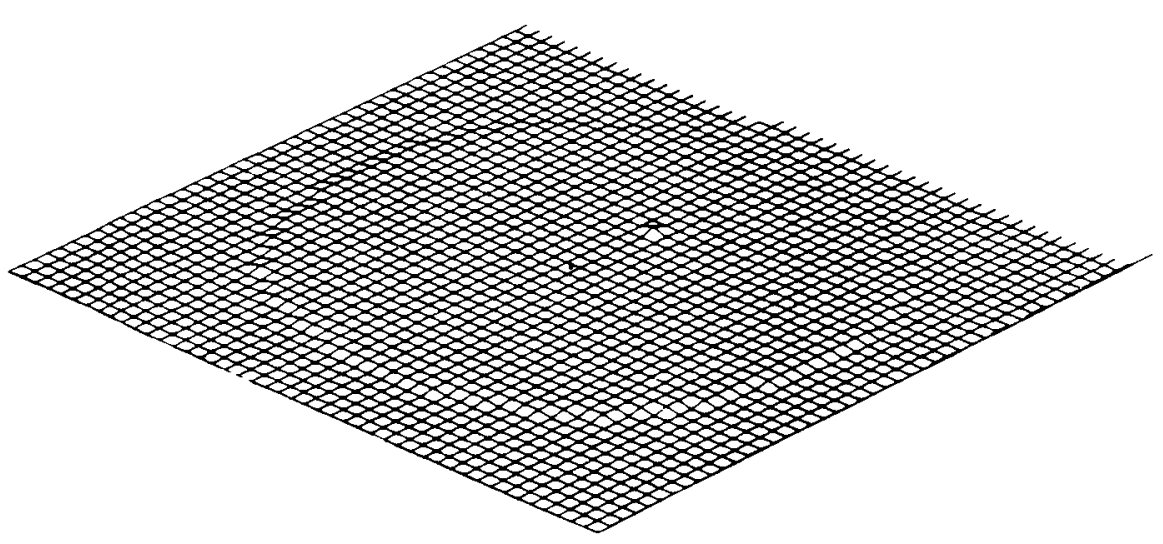

FIGUAE 5. Error in the z-value of the Calculated Reflector Surface when Edge Diftracted Fields are Noglocted 


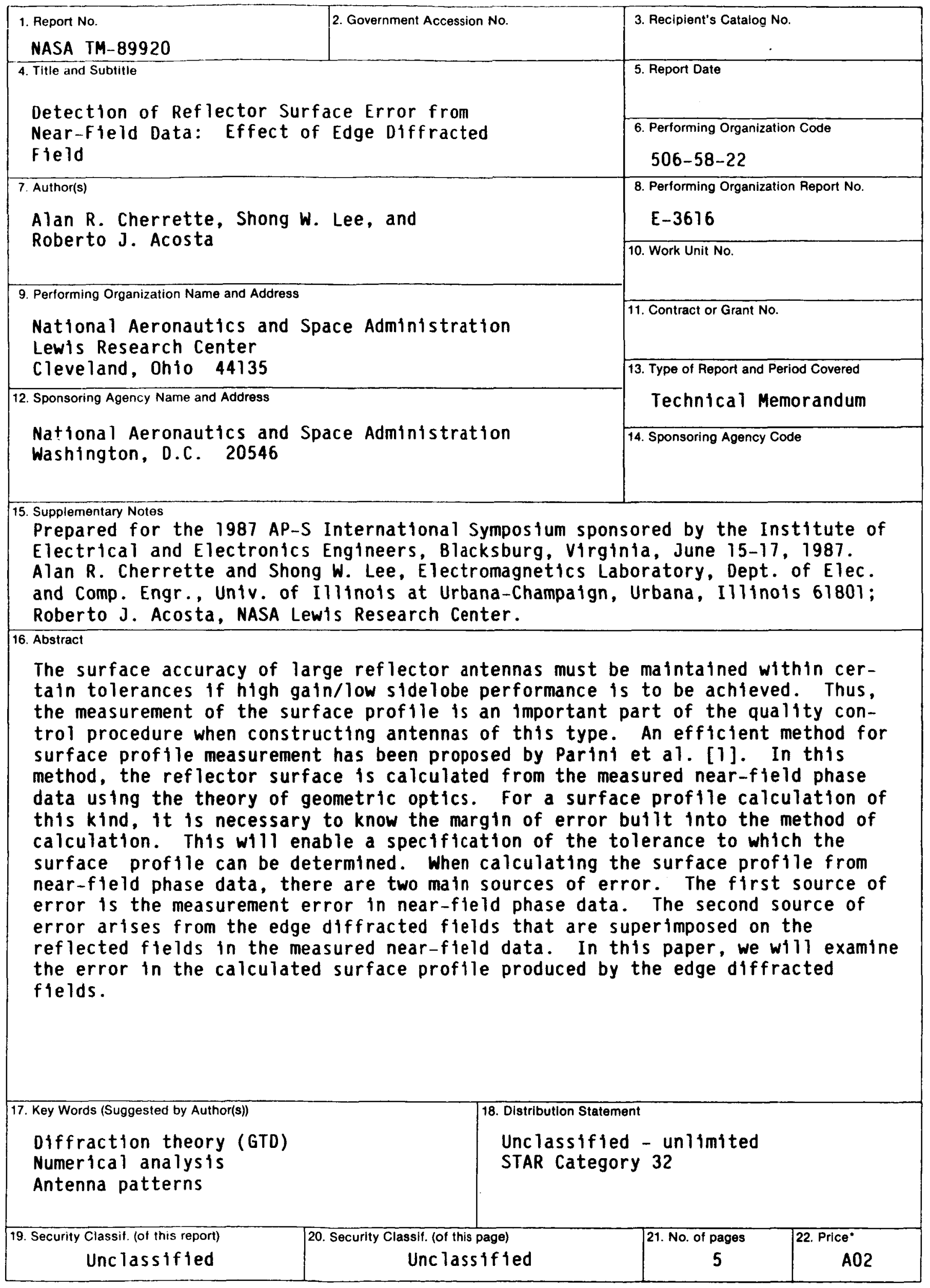

"For sale by the National Technical Information Service, Springfield, Virginia 22161 